\title{
Study on Change of Quantity of Cultivated Land and Its Driving Forces in Sichuan Province in the Recent 15 Years
}

\author{
Er-li-sai $\mathrm{Mu}^{1} \&$ Wen-kuan $\mathrm{Chen}^{1}$ \\ ${ }^{1}$ College of Economics and Management, Sichuan Agricultural University, Chengdu, China \\ Correspondence: Er-li-sai Mu, College of Economics and Management, Sichuan Agricultural University, \\ Chengdu 611130, China. E-mail: 6211663@qq.com
}

Received: July 20, 2012 Accepted: August 6, 2012 Online Published: August 30, 2012

doi:10.5539/ass.v8n11p234

URL: http://dx.doi.org/10.5539/ass.v8n11p234

\begin{abstract}
This paper takes the cultivated land in Sichuan Province as the research object based on the statistical data about cultivated land between 1995 and 2009, selects eight variable factors that affect change of the quantity of cultivated land, uses the principal component analysis to analyze the direct correlation between different factors, puts forward the two driving factors of economy and population and then sets up a binary regression model to make a quantitative analysis of the overall value of the principal component factors abstracted. The result shows that, the quantity of cultivated land in Sichuan Province has undergone a change process of slow reduction sharp reduction - slow increase. Economic factor and population factor are the most important driving factors that affect change of quantity of cultivated land in Sichuan Province and they are both negatively correlated with change of cultivated land. The model shows that, the overall influences of these two types of driving forces are still constantly increasing, but influence of the economic driving force on cultivated land is weakened.
\end{abstract}

Keywords: quantity of cultivated land, change, driving forces, factor

\section{Premise}

In the 1990s, economy in Sichuan Province entered a high speed stage of development. With acceleration of the progress of urbanization, great changes also have taken place in quantity of cultivated land. As a big agricultural province, the dynamic change in the allocation of cultivated land resources in Sichuan Province, without doubt, is the key to affect sustainable development of its own and even the entire western area. Thus, study on rules and reasons for reduction of quantity of cultivated land will contribute to coordinate and alleviate contradictions between economic development and reduction of cultivated land in Sichuan Province and will also help to predict the driving forces and factors in change of quantity of cultivated land in the future.

\section{Research Methodology}

\subsection{Principal Component Analysis (PCA)}

This paper mainly employs the principal component analysis (PCA). It is mainly to reduce dimensionality of multiple original indicators that have certain correlation and convert them to a few overall indicators. These new indicators will reflect information about the original variables as much as possible and they are mutually independent. The major procedure of PCA is as follows:

1) Standardization of data. Standardization of data is also termed as non-dimensionalization. That is, value of all indicators with different measurement is respectively converted to non-dimensional relative value of indicators. We employ the statistical software SPSS17.0 to conduct standardization conversion to the data.

2) KMO- Bartlett test of sphericity. KMO (Kaiser-Meyer-Olkin) statistic is used to compare the simple correlation coefficient and partial correlation coefficient of variables and its value is between o and 1 . If the value approximates to 1, it indicates that the correlation of the original variables is strong and the original variables are suitable for factor analysis. Kaiser presented the frequently used kmo measurement standard: measurement above 0.9 indicating quite suitable; measurement of 0.8 indicating suitable; measurement of 0.7 indicating common; measurement of 0.6 indicating not quite suitable and measurement below 0.5 indicating quite unsuitable. 
3) To calculate the eigenvalue of correlation coefficient matrix, contribution rate and accumulative contribution rate of original variables.

4) To abstract and nominate dominant factor. If the accumulative contribution rate is larger than or equal to $85 \%$, then the dominant factor can be abstracted to become a principal component factor and the factors with the highest correlation is used to nominate the principal component.

5) To calculate the overall score of the factors. We calculate the score coefficient of the factors according to the score load matrix of the factors and establish factor overall score equation. Then we calculate the overall evaluation model (Equation 3) of the principal component by regarding as the weight the proportion of the eigenvalue of each principal component to the total eigenvalue of the principal components abstracted, weigh and collect public factors and get the overall score of driving forces.

$$
F=\frac{\lambda 1}{\lambda 1+\lambda 2} F 1+\frac{\lambda 2}{\lambda 1+\lambda 2} F 2
$$

(Equation 1)

Where, $\lambda \mathrm{i}$ stands for the eigenvalue $(\mathrm{i}=1,2)$ of the $\mathrm{i}^{\text {th }}$ principal component factor

\subsection{Binary Linear Regression Analysis}

The basic principle of binary linear regression analysis is to assume that linear relationship exists between the explained variable $\mathrm{Y}$ and the two independent variables $\mathrm{X} 1$ and $\mathrm{X} 2$, and the mathematical model is as follows:

$$
\mathrm{Y}=\mathrm{a} 0+\mathrm{a} 1 \mathrm{X} 1+\mathrm{a} 2 \mathrm{X} 2+\mu
$$

Where, $\mathrm{Y}$ is an explained variable, $\mathrm{Xi}(\mathrm{i}=1,2)$ are two explanatory variables, $\mathrm{a}(\mathrm{a}=0,1,2)$ are three unknown parameters and $\mu$ is a random error item.

The linear equation between the explained $\mathrm{Y}$ and $\mathrm{X} 1$ and $\mathrm{X} 2$ is shown as below:

$$
\mathrm{E}(\mathrm{Y})=\mathrm{a} 0+\mathrm{a} 1 \mathrm{X} 1+\mathrm{a} 2 \mathrm{X} 2
$$

We use a group of $n(i=1,2)$ observation value to work out the undetermined coefficients a1 and a2 of the above equation according to the principle of least square.

\section{Dynamic Change of Quantity of Cultivated Land in Sichuan Province and an Analysis of Driving Forces}

\subsection{Summary of Research Area}

Sichuan Province is located in southwestern China and upper Yangtze River. It is between the east longitude $92^{\circ} 21^{\prime}-108^{\circ} 12^{\prime}$ and northern latitude $26^{\circ} 03^{\prime}-34^{\circ} 19^{\prime}$. It is 1075 kilometers long from the east to the west and more than 900 kilometers wide from the south to the north. It is connected to Chongqing in the east, neighboring to Yunnan and Guizhou in the south, to Tibet in the west and neighboring to the three provinces of Qinghai, Gansu and Shaanxi in the north. It has an area of 485 thousand square kilometers which accounts for $5.1 \%$ of the total area of the national territory and it ranks the fifth in the whole country. Its geomorphic type is quite complicated, characterized by mountains and plateau, and it has the four types of geomorphic types of mountain land, hill, plain and plateau, which respectively occupy $77.1 \%, 12.9 \%, 5.3 \% \& 4.7 \%$ of the total area of the whole province. Its land utilization is mainly forest and animal husbandry and its forestry and animal husbandry land is mainly distributed in mountain area and western high mountains and plateau, accounting for $69.2 \%$ of the total land area. Its cultivated land is mainly distributed in the eastern basin and low mountain and hill area, accounting for more than $85 \%$ of the total cultivated land of the whole country. Its garden plot is mainly distributed in the basin hill and southwestern mountain area, accounting for more than $70 \%$ of the garden plot in the whole province. Its traffic land and residential area is mainly distributed in the economically developed plain area and hill area. According to the data statistics, by the end of 2009, the total population in Sichuan Province was 81.85 million and its agricultural population was 66.984 million. Its per capita land area was lower than the average level of the whole country and its contradict of large population and small land area was quite outstanding.

\subsection{Source of Data}

Data in this paper are collected from the data base of the National Statistics Bureau of China and "Sichuan Statistical Yearbook" (1996-2010).

\subsection{Trend of Dynamic Change of Quantity of Cultivated Land in Sichuan Province}

According to the data of indicators in "year-end actual area of cultivated land" in "Sichuan Statistical Yearbook", the area of cultivated land in Sichuan Province declined steadily in 1999. It is shown in Figure 1, the area of cultivated land between 1990 and 1996 declined slowly, while the quantity of cultivated land between 1997 and 2003 declined sharply. And each year, an average area of 102.7 thousand hectares of cultivated land was lost. 
Then, from 2004 to 2009, the area of cultivated land began to increase on a small margin. Thus, it can be found that, the area of cultivated land in Sichuan Province had approximately gone through the process of slow reduction - sharp reduction - increase on a small margin and the whole fluctuation of change was large. From 1995 to 2009, a net area of 584.3 hectares of cultivated land was lost in Sichuan Province and each year, an average area of 39 thousand hectares was lost. A net area of 243.2 hectares of paddy field was lost, accounting for $41.6 \%$ of the total loss. Nevertheless, from the year 2005, the area of cultivated land began to increase year by year, but the increase was not obvious.

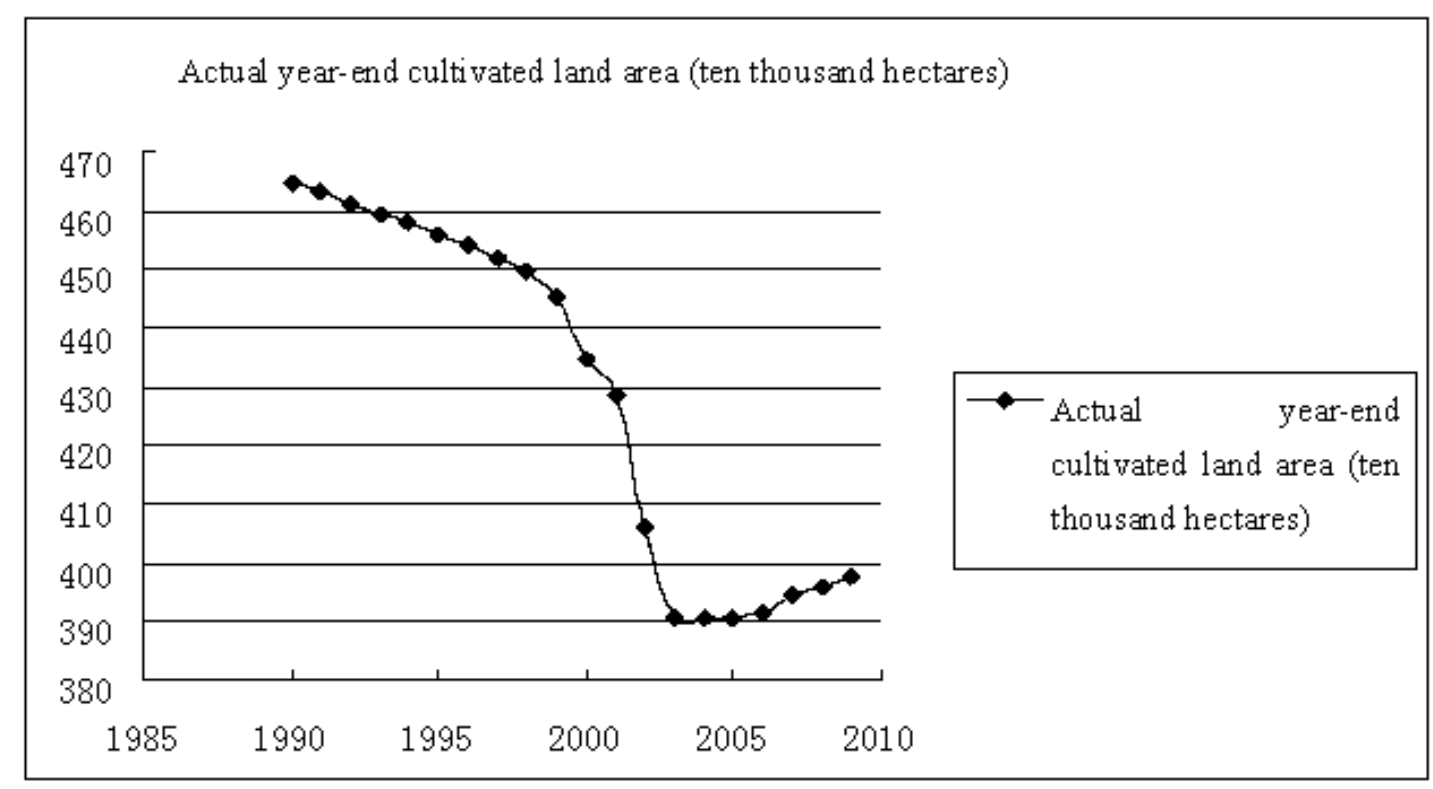

Figure 1.

According to the data of indicators in "Per capita cultivated land area in rural families" (Figure 3) in "Sichuan Statistical Yearbook", the trend of change in per capita cultivated land area in rural families in Sichuan Province between 1995 and 2009 was identical with the trend of change in per capita cultivated land area at the same period. Although the total population of Sichuan Province has presented a tendency of decline, the per capita cultivated land area and cultivated land situation were not optimistic since the total area of cultivated land was also constantly declining. During the 15 years, the per capita cultivated land area of 0.94 hectare / person was the lowest in 2003 and the per capita cultivated land area was the highest in 1994, which was only 1.26 hectares / person. From 2001 to 2006, the per capita cultivated land area in rural families was lower than 1 hectare / person. From Figure 4, it can be seen that, except that the per capita cultivated land in Sichuan Province was higher than 0.05 hectare / person from 1997 to 2000, the per capita cultivated land in other years was all lower than the warning limit of 0.05 hectare / person as prescribed by the United Nations. Thus, the contradiction between population and land is quite prominent and reserve resources are in great shortage.

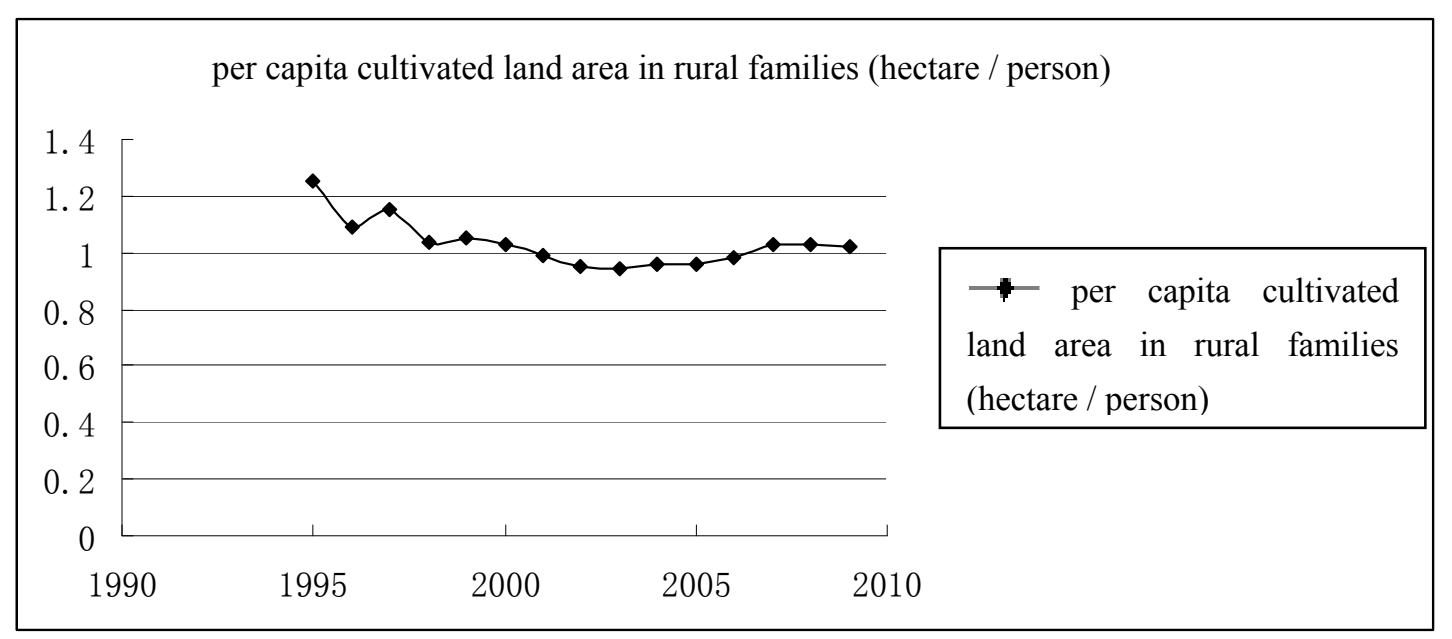

Figure 2. Per capita cultivated land area in rural families (hectare / person) 


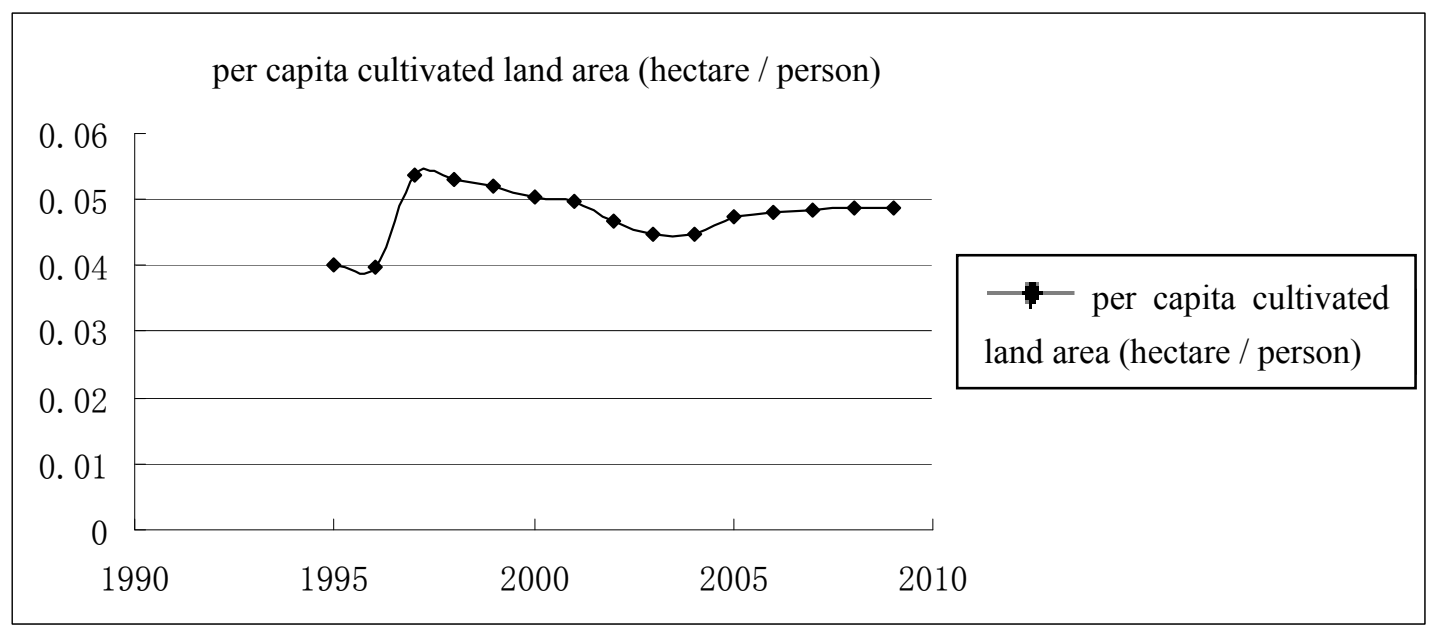

Figure 3. Per capita cultivated land area (hectare / person)

\subsection{An Analysis of Driving Forces in Change of Quantity of Cultivated Land}

\subsubsection{CPA}

There are various and complicated driving factors that affect change of cultivated land area, including population, economic, social, natural and policy factors. Yet, these factors do not only have different degrees of correlation with the area of cultivated land, but also have coupling correlation with each other. Therefore, a pure correlation analysis is not likely to resolve redundancy of errors. Then, we choose the PCA to compress multiple variables into a few independent components so as to weaken mutual interference of all different variables. Simultaneously, we make linear combination of multiple indicators that affect the area of regional cultivated land, reduce the original variables to a few new and representative variables, and replace the multiple indicators with a few indicators. This can not only more intensively and typically show the features of the research objects, but can also avoid a lot of repeated work. Hence, based on the principle and requirement of PCA and the current data about Sichuan Province, we choose the sequential data between 1995 and 2009 as the fundamental data and, therefrom, select eight influencing factors, namely, X1: year-end total population (ten thousand persons), X2: non-agricultural population (ten thousand persons), X3: GDP(0.1 billion Yuan), X4: total industrial production value ( 0.1 billion Yuan), X5: production value in building industry ( 0.1 billion Yuan), X6: land area of national capital construction (thousand hectares), X7: highway landline (kilometer) and X8: disaster area (ten thousand hectares). (See Table 1)

Table 1. Driving factors and indicators of change in quantity of cultivated land

\begin{tabular}{lccc}
\hline Evaluation goal & Factor & Indicator & No. \\
\hline & & Year-end total population & $\mathrm{X} 1$ \\
& Population factor & Non-agricultural population & $\mathrm{X} 2$ \\
& & GDP & $\mathrm{X} 3$ \\
& & Total industrial production value & $\mathrm{X} 4$ \\
& & Production value in building industry & $\mathrm{X} 5$ \\
& Social factor & Land area of national capital construction & $\mathrm{X} 6$ \\
& Ecological factor & Highway landline & $\mathrm{X} 7$ \\
& Disaster area & $\mathrm{X} 8$ \\
\hline
\end{tabular}

We take the above data about variable factors between 1995 and 2009 as the analysis sample and employ the software SPSS17.0 to make a statistical analysis and get correlation coefficient matrix, sphericity test, eigenvalue, contribution rate and accumulative contribution rate of principal components and load matrix of principal components. 
Table 2. Relevant matrix

\begin{tabular}{lrrrrrrrr}
\hline & $\mathrm{X} 1$ & $\mathrm{X} 2$ & $\mathrm{X} 3$ & $\mathrm{X} 4$ & $\mathrm{X} 5$ & $\mathrm{X} 6$ & $\mathrm{X} 7$ & $\mathrm{X} 8$ \\
\hline $\mathrm{X} 1$ & 1.000 & & & & & & \\
$\mathrm{X} 2$ & -.619 & 1.000 & & & & & & \\
$\mathrm{X} 3$ & -.530 & .952 & 1.000 & & & & & \\
$\mathrm{X} 4$ & -.477 & .921 & .995 & 1.000 & & & & \\
$\mathrm{X} 5$ & -.556 & .965 & .997 & .987 & 1.000 & & \\
X6 & -.403 & .471 & .606 & .620 & .613 & 1.000 & \\
X7 & -.350 & .870 & .966 & .976 & .954 & .615 & 1.000 & \\
X8 & .412 & -.786 & -.777 & -.767 & -.768 & -.408 & -.711 & 1.000 \\
\hline
\end{tabular}

It can be found from Table 2, correlation of different degrees exists among the nine factors that affect quantity of cultivated land. High correlation exists between X3 and X4 and X5 and the correlation coefficients are respectively 0.995 and 0.997 . This proves necessity of PCA.

Table 3. KMO and Bartlett test of sphericity

\begin{tabular}{|c|c|c|}
\hline Sample enough Kaiser-M & nent. & .752 \\
\hline Bartlett test of sphericity & Approximate chi-square & 228.366 \\
\hline & $\mathrm{df}$ & 28 \\
\hline & Sig. & .000 \\
\hline
\end{tabular}

It can be found that KMO and result of Bartlett test of sphericity in Table 3, the probability P in Bartlett test of sphericity has a value of 0.000 , indicating the hypothesis is rejected. That is, there is significant difference between correlation coefficient matrix and unit matrix. Meanwhile, KMO has a value of 0.752 . It is, thus, known that the original variable is suitable for factor analysis according to the measurement standard of KMO.

Table 4. Total explained variance

\begin{tabular}{|c|c|c|c|c|c|c|c|c|c|}
\hline \multirow{2}{*}{$\begin{array}{c}\text { Compo } \\
\text { nent }\end{array}$} & \multicolumn{3}{|c|}{ Initial eigenvalue } & \multicolumn{3}{|c|}{ Abstract square and load } & \multicolumn{3}{|c|}{ Revolve square and load } \\
\hline & Total & $\begin{array}{c}\% \text { of } \\
\text { variance }\end{array}$ & $\begin{array}{c}\text { Accumulati } \\
\text { ve } \%\end{array}$ & Total & $\begin{array}{c}\% \text { of } \\
\text { variance }\end{array}$ & $\begin{array}{c}\text { Accumulati } \\
\text { ve } \%\end{array}$ & Total & $\begin{array}{c}\% \text { of } \\
\text { variance }\end{array}$ & $\begin{array}{l}\text { Accumulati } \\
\text { ve } \%\end{array}$ \\
\hline 1 & 6.178 & 77.231 & 77.231 & 6.178 & 77.231 & 77.231 & 5.274 & 65.922 & 65.922 \\
\hline 2 & .760 & 9.502 & 86.733 & .760 & 9.502 & 86.733 & 1.665 & 20.812 & 86.733 \\
\hline 3 & .662 & 8.272 & 95.005 & & & & & & \\
\hline 4 & .332 & 4.147 & 99.153 & & & & & & \\
\hline 5 & .052 & .646 & 99.799 & & & & & & \\
\hline 6 & .014 & .177 & 99.976 & & & & & & \\
\hline 7 & .002 & .021 & 99.996 & & & & & & \\
\hline 8 & .000 & .004 & 100.000 & & & & & & \\
\hline
\end{tabular}

Abstract method: PCA.

It can be seen from Table 4, the contribution rate of the first principal component is $77.231 \%$ and the contribution rate of the second principal component is $9.502 \%$. The accumulative contribution rate of the first and second principal components have attained $86.733 \%$. According to the principle that the accumulative contribution rate should be above or equal to $85 \%$, only the first two principal components are needed to well summarize this group of data. Thus, we get the correlation coefficient between the principal components and 
variables, namely, principal component load matrix (See Table 5).

Table 5. Component load matrix

\begin{tabular}{lrc}
\hline & \multicolumn{2}{c}{ Component } \\
\cline { 2 - 3 } X1: year-end total population (ten thousand persons) & 1 & 2 \\
X2: non-agricultural population (ten thousand persons) & -.592 & .789 \\
X3: GDP(0.1 billion Yuan) & .955 & -.036 \\
X4: total industrial production value (0.1 billion Yuan) & .991 & .081 \\
X5: production value in building industry (0.1 billion Yuan) & .981 & .137 \\
X6: land area of national capital construction (thousand hectares) & .992 & .045 \\
X7: highway landline (kilometer) & .660 & -.160 \\
X8: disaster area (ten thousand hectares) & .943 & .262 \\
\hline Abtrat & -.815 & -.123
\end{tabular}

Abstract method: PCA.

a. 2 components are abstracted.

From the first principal component, it can be seen, there is strong positive correlation between the first principal component and X3: GDP, X4: total industrial production and X5: production value in building industry; from the second principal component, it can be seen, there is strong positive correlation between the second principal component and X1: total population. X3: GDP, X4: total industrial production and X5: production value in building industry belong to economic driving factors, whereas $\mathrm{X} 1$ : total population belongs to population driving factor. Nevertheless, in the first principal component, X2: non-agricultural population also has strong positive correlation, namely, 0.955 . Thus, the major driving factors for change of the area of cultivated land in Sichuan Province are economic driving factors and population driving factors.

\subsubsection{Economic Driving Factor}

Ever since 1990s, the economic strength in Sichuan Province has been growing rapidly and its GDP increased from 244.321 billion Yuan in 1995 to 1415.128 billion Yuan in 2009, with an increase of almost five times. Its production value in building industry increased from 14.774 billion Yuan in 1995 to 103.363 billion Yuan in 2009 , with an increase of six times. Its other economic indicators have also increased on a large margin during the successive 15 years. Therefore, the dynamic factor of economic development is one of the major factors for the change of quantity of cultivated land. It can be found from the first principal component, there is high correlation between GDP, total industrial value and production value in building industry and the first principal component, especially the prominent influences of GDP and production value in building industry. This indicates that economic development driving is the primary factor for reduction of cultivated land. With propelling of urbanization and industrialization, people have higher demand on housing, public infrastructure, and the urban cities are constantly extended and expanded, which causes the surrounding plenty of cultivated land is occupied and the contradiction between population and land in agricultural production becomes increasingly intense.

\subsubsection{Population Driving Factor}

Population factor is a primary factor that constitutes the second principal component, one of the major driving forces in change of quantity of cultivated land, and, to some extent, it gives rise to rapid reduction of cultivated land. The proportion of non-agricultural population in Sichuan Province has been on a constant increase year by year. The total population in Sichuan Province in 1995 was 113.25 million and non-agricultural population was 13.318 million. By the year 2009, the total population in Sichuan Province was 81.85 million and non-agricultural population was 22.863 million. The ratio of non-agricultural population to the total population increased from $11.8 \%$ to $27.9 \%$. From the data about per capita cultivated land area in Figure 3, it can be seen that, as a matter of fact, the pressure of population growth that causes reduction of cultivated land in Sichuan Province is as a result of change in de-agriculturalization of the population. The direct effect of growth in urban population and improvement of the level of urbanization is that demand on housing construction land is sharply enlarged and plenty of cultivated land is occupied. 
Table 6. Score coefficient load matrix of components

\begin{tabular}{lrc}
\hline & \multicolumn{2}{c}{ Component } \\
\cline { 2 - 3 } X1: year-end total population (ten thousand persons) & 1 & 2 \\
X2: non-agricultural population (ten thousand persons) & .336 & -.986 \\
X3: GDP(0.1 billion Yuan) & .122 & .106 \\
X4: total industrial production value (0.1 billion Yuan) & .190 & -.032 \\
X5: production value in building industry (0.1 billion Yuan) & .219 & -.100 \\
X6: land area of national capital construction (thousand hectares) & .171 & .011 \\
X6: land area of national capital construction (thousand hectares) & .012 & .236 \\
X8: disaster area (ten thousand hectares) & .280 & -.252 \\
\hline Abstat & -.186 & .093 \\
\hline
\end{tabular}

Abstract method: PCA.

Revolve method: maximum variance and constituent score of normalization of Kaiser

According to score coefficient load matrix of principal component (Table 6), we can get the equations (Equation 2 and Equation 3) of the overall score of the two principal component factors:

$$
\begin{aligned}
& \mathrm{F} 1=0.336 \mathrm{X} 1+0.122 \mathrm{X} 2+0.190 \mathrm{X} 3+0.219 \mathrm{X} 4+0.171 \mathrm{X} 5+0.012 \mathrm{X} 6+0.280 \mathrm{X} 7-0.186 \mathrm{X} 8 \\
& \mathrm{~F} 2=-0.986 \mathrm{X} 1+0.106 \mathrm{X} 2-0.032 \mathrm{X} 3-0.100 \mathrm{X} 4+0.011 \mathrm{X} 5+0.236 \mathrm{X} 6-0.252 \mathrm{X} 7+0.093 \mathrm{X} 8
\end{aligned}
$$

(Equation 3)

We calculate the overall evaluation model (Equation 1) of the principal component by taking as the weight the ratio of the eigenvalue of each principal component to the total sum of the eigenvalue of principal components abstracted and weigh and collect the two public factors. Then, we get the overall score of driving forces in change of utilization of cultivated land each year in Sichuan Province (See Figure 4).

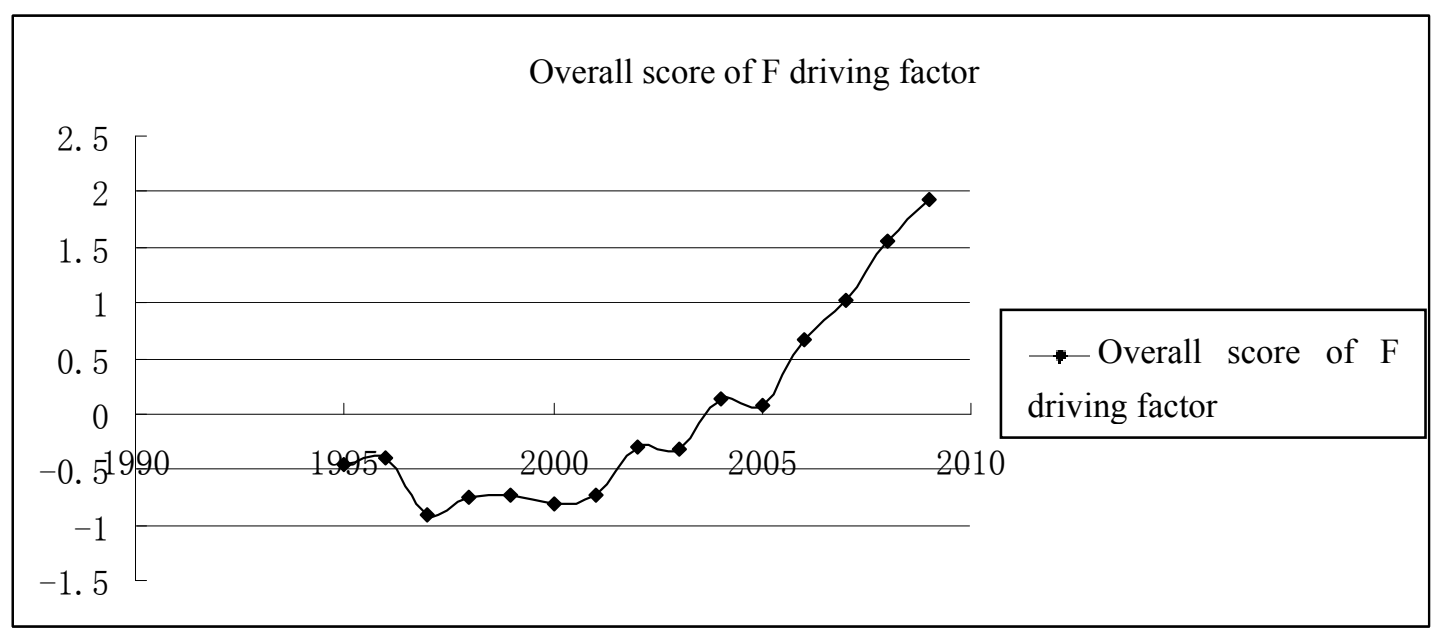

Figure 4.

It can be seen from Figure 5, the overall tendency of influences of de-agriculturalization economic and population driving forces that affect cultivated land in Sichuan Province between 1990 and 2009 gradually increases. The overall scores of driving forces prior to 2004 are all negative, respectively $-0.45,-0.39,-0.90$, $-0.75,-0.73,-0.82,-0.74,-0.30,-0.32$. From the year 2004, the overall scores of driving forces began to become positive, respectively $0.13,0.08,0.66,1.03,1.55,1.92$. The overall scores of driving forces between 1997 and 2001 did not show an obvious fluctuation. This indicates that during that period, influences of the driving forces on quantity of cultivated land were not obvious, but the overall scores of the driving forces between 2001 and 
2009 began to increase year by year, and rapidly increased especially from 2005 . This shows that, influences upon cultivated land expedited transfer of de-agricultralization with development of economy and growth of population pressure. Thus, it can be predicted that, economic driving force and population driving force will become predominant factors that affect change of quantity of cultivated land and their influencing forces will continue to increase.

\subsubsection{Binary Regression Analysis}

In order to weaken influences of the colinearity relationship between different indicators on multiple regression analysis, this paper abstracts the overall value of principal components through analysis of factors and then makes a binary regression analysis with the area of cultivated land. The overall value of the two principal components is respectively F1 (economic indicator) and F2 (population indicator). Then, this paper makes a binary linear regression analysis of principal components and area of cultivated land (data ' $\mathrm{Y}$ ' after standardization) with the statistical software SPSS 17.0. The analysis result is shown in Table 7.

Table 7. Coefficient

\begin{tabular}{|c|c|c|c|c|c|c|}
\hline \multirow[b]{2}{*}{ Mod } & & \multicolumn{2}{|c|}{ Unstandardized coefficients } & $\begin{array}{l}\text { Standardized } \\
\text { coefficients }\end{array}$ & \multirow[t]{2}{*}{$\mathrm{t}$} & \multirow[t]{2}{*}{ Sig. } \\
\hline & & B & Standard Error & Beta & & \\
\hline 1 & (constant) & 418.504 & 4.913 & & 85.180 & .000 \\
\hline & F1 & -19.472 & 5.705 & -.631 & -3.413 & .005 \\
\hline & F2 & -110.343 & 46.421 & -.439 & -2.377 & .035 \\
\hline
\end{tabular}

a. Dependent variable: $y:$ actual year-end cultivated land area (ten thousand hectares)

We can get a standardized multiple linear regression model from Table 7, as shown in Equation 4.

$$
\mathrm{Y}^{\prime}=418.504-19.472 \mathrm{~F} 1-110.343 \mathrm{~F} 2
$$

(Equation 4)

The multiple correlation coefficient of the model $\mathrm{R}=0.768$ and the coefficient of determination after adjustment $\mathrm{R}^{2}=0.690$ both have passed the significance level test. That is to say, the regression effect of the model is of high significance.

It can be seen from Equation 4, the quantity of cultivated land is negatively correlated with F1 and F2. That is to say, when F1 and F2 grow, the quantity of cultivated land is reduced and vice versa. The coefficient of the regression model reflects the sensibility of change of cultivated land to the driving factors. The correlation coefficient between economic indicator F1 and Y is relatively small. That is because, on one hand, economic development requires a large quantity of cultivated land for construction in the process of urbanization, and, on the other hand, the society has invested enormous financial resources to protect cultivated land and satisfy demand of population on materials, such as, returning the grain plots to forestry, modification of medium-and-low-yield land and land reclamation, etc., to increase the quantity of cultivated land.

\section{Conclusion}

Through an analysis of the dynamic change of quantity of cultivated land in Sichuan Province and the driving factors, this paper comes to the following conclusions:

1) The change of quantity of cultivated land in Sichuan Province presents a condition of slow reduction - sharp reduction -slow increase.

2) Reduction of quantity of cultivated land is comprehensively affected by multiple factors, such as, population, economy, society and ecology, etc. However, the primary reason lies in rapid development of economy, expedition of industrialization and urbanization, which leads to sharp expansion of urban areas. Then, it is the constant growth of urban population, which directly leads to increasing demand of population on the residential land.

3) From the year 2001, the quantity of cultivated land in Sichuan Province was more and more affected by economic and population driving forces. Especially after 2005, the influences became more obvious and are continuously increasing.

4) In the process of influencing reduction of cultivated land, although economic driving factor generally is a primary factor that leads to reduction of cultivated land, the influential effect is still weakened. And the quantity 
of cultivated land in Sichuan Province gradually returns to increase, but the increase margin is not obvious.

\section{References}

Duan, Wenji, He, Feng, \& Li, Xiaocun. (2007). Study on Characteristic and Driving Forces of Cultivated Land Dynamic Change in Tai' an. China Population Resources and Environment, 17(2), 111-114.

Guo, Honghai, \& Song, Min. (2009). Analysis on Dynamic Changing Trend of Arrable Land in Shandong Province and Its Driving Force. China Journal of Agricultural Resources and Regional Planning, 30(1), 51-57.

He, Dan, \& Diao, Chentai. (2006). Analysis of Land Use Changes and Social Driving Forces in Jiangjin, Chongqing. Research of Soil and Water Conservation, 13(2), 24-26.

Li, Jianqiang et al. (2004). Study on Process of Change in Quantity of Cultivated Land in Sichuan Province and Its Driving Forces. Journal of Sichuan Agricultural University, 22(1).

Liu, Qing et al. (2010). Econometric Analysis on Driving Forces of Cultivated Land Quantity Change in Changsha-Zhuzhou-Xiangtan Urban Agglomerations. Resources Science, 32(9), 1734-1740.

Liu, Tao et al. (2009). Analysis of the Changes of Cultivated Land and Its Factors on Hantai District of Shaanxi Province from 1978 to 2006. Resources Science, 31(5), 816-823.

Zhang, Hongbin, Jia, Laixi, \& Li, Lu. (2009). SPSS Book. Beijing: Electronic Industry Press. 